\title{
Disorders of Sexual Development: Presentation and Categorization at Allied Hospital / Punjab Medical College Faisalabad, Pakistan
}

\author{
Muhammad Irfan Munir, Muhammad Akmal, Ghulam Mahboob Subhani, Safdar Hassan Javed, Ashraf Ali Jafari, Muhammad
} Tahir Bashir Malik

\begin{abstract}
Background: Ambiguous genitalia is a condition in which external genitalia of the patients are ambiguous (not clearly male or female) or their external genitalia do not match with the chromosomal sex. It's a rare condition and its incidence is $1.7 \%$, or others say $1 / 5500$ live births. Current nomenclature defines it as "disorder of sexual development" (DSD). It is generally divided into six categories; 46 XY DSD,46 XX DSD, chromosomal DSD, ovotesticular DSD, 46 XY complete gonadal dysgenesis \& 46XX testicular DSD. I_DSD registry (Glasgow) is the largest organization which registers such cases for clinical research and standardizes the information. Data from 51 centers from 36 countries across the globe is being uploaded there. Urology Department of Allied Hospital Faisalabad is the only center from Pakistan which registers its cases. Objectives: To identify and categorize different presentations of DSD according to the standard nomenclature. 2-To register the cases of DSD to I-DSD registry in Glasgow to be included in further clinical research. Study Design: Retrospective study. Settings: Urology Department Allied Hospital Faisalabad, Pakistan. Duration: From 01-092008 to 31-08-2019. Inclusion Criteria: All the patients with indeterminate sex / ambiguous genitalia presenting to OPD of Allied hospital Faisalabad irrespective of age Exclusion Criteria: Patients previously operated for DSD / with unrecorded data at first presentation. Methodology: Relevant data was retrieved from patients' charts taken from hospital records, with the permission of hospital administration to publish their data. Patients had been evaluated with history/examination for phenotypical sex, with karyotyping for chromosomal sex, and ultrasonography \& hormonal analysis (serum testosterone, FSH, LH and Estradiol) for gonadal sex. Specific tests like 17-OH levels performed in selected patients (CAH). Gender assignment was done according to chromosomal sex, after counselling of parents and adult patients. Results: Total 34 patients were enrolled. Mean age at presentation was $16.38 \pm 9.38$ years (range 10 months to 42 years). Nine of 34 patients were brought up as females, one as intersex and 24 as males. After categorization of various clinical presentations according to standard nomenclature, $27(79.4 \%)$ belonged to 46XY DSD category, 03(8.80\%) to 46XX DSD, $02(5.88 \%)$ to chromosomal DSD, 01(2.90\%) was 46XY complete gonadal dysgenesis and 01(2.90\%) patient belonged to ovo-testicular DSD. None of the patients had 46XX testicular DSD. Among the presumed female patients, six were chromosomally male and were having perineal hypospadias and were later assigned the male gender. Among the presumed male patients, two were diagnosed as CAH patients with XX genetic makeup. Three patients were having exstrophy epispadias complex, 15 patients were having perineal hypospadias (majority with undescended testes) and 7 had penoscrotal hypospadias. Conclusion: Identification \& categorization of indeterminate sex and gender assignment is mandatory for social \& psychological well-being of patients and their families.
\end{abstract}

Keywords: Ambiguous Genitalia, I-DSD, CAH, Intersex.

Corresponding Author

Submitted for Publication: 16-02-2020

Accepted for Publication:21-03-2020

DR. MUHAMMAD IRFAN MUNIR, Associate Professor, Urology, Faisalabad Medical University / Allied Hospital, Faisalabad-Pakistan.

Contact / Email: +92 333-6701970, driffanmunir1970@gmail.com

Citation: Munir MI, Akmal M, Subhani GM, Javed SH, Jafari AA, Malik MTB. Disorders of Sexual Development; Presentation and Categorization

Based on Karyotyping: 11 years' Experience at Allied Hospital/Punjab Medical College Faisalabad, Pakistan. APMC 2020;14(1):70-3.

\section{INTRODUCTION}

Ambiguous Genitalia is defined as: a condition in which external Genitalia are indiscriminate (not clearly male or female or external genitalia do not match with the chromosomal sex. (1,2 $^{1,2}$ terminology has changed from, intersex to "Ambiguous Genitalia" to DSD (Disorders of Sexual Development). It is rare disorder but common in certain parts of world e.g. Gaza Strip of Palestine where gender change at 11 years to puberty is common. ${ }^{3}$ In 9th \& 10 th week of gestation, Leydig cells develop from genital ridge mesenchyme ${ }^{4}$ and Sertoli cells secrete Mullerian Inhibitory Substances (MIS) at 11 weeks of gestation. The local testosterone produced has paracrine effect on local internal genitalia leading to development of Wolffian duct and development of male internal genitalia's (epididymis, vas deference, prostate and seminal vesicles) and MIS lead to regression of Mullerian duct. In the absence of testosterone, internal gonads develop as female with the development of
Mullerian duct into uterus, fallopian tubes, ovaries and upper third of vagina.

All these changes are determined by SRY (on short arm of $Y$ chromosome) the gene encoding for testis. Hence, SRY determines the gender. Similarly, its shift to $\mathrm{X}$ chromosome can lead to development of male behaviors (female with testis).

Females exposed to androgens / progesterone during pregnancy can also lead to DSD with masculinization of female fetus. Subjects may be insensitive to effects of testosterone and $\mathrm{XY}$ male may develop as female.

Any enzymatic defect in the production of cortisol, aldosterone and androgens lead to negative feedback and excess production of ACTH and pre-block accumulation of metabolites leading to $\mathrm{CAH}$ in a female child with hypertrophy of clitoris looking like a male with or without fused labia. This may be life threatening in salt loosing variety. All of above-mentioned conditions lead to Ambiguous Genitalia. 5,6 
The enzymatic defects responsible for congenital adrenal hyperplasia are 21 hydroxylases deficiency, 11 hydroxylase deficiency and 3 beta steroid dehydrogenase deficiency. As these leads to deficiency of different hormones like mineralocorticoids and glucocorticoids, these hormones need to be replaced in these patients especially fludrocortisone, maybe for life time. ${ }^{7}$ As its terminology keeps on changing, recent nomenclature with previous nomenclature is as below. ${ }^{8}$

\begin{tabular}{|l|l|}
\hline Current Nomenclature & Old Nomenclature \\
\hline 46, XX DSD & $\begin{array}{l}\text { Female } \\
\text { pseudohermaphrodite }\end{array}$ \\
\hline 46XY, DSD & Male pseudohermaphrodite \\
\hline Ovotesticular DSD & True hermaphrodite \\
\hline $\begin{array}{l}\text { 46 XY, Complete gonadal } \\
\text { dysgenesis }\end{array}$ & XY Sex Reversal \\
\hline 46, XX Testicular DSD & XX Sex Reversal \\
\hline
\end{tabular}

Persistent Mullerian duct syndrome (an autosomal recessive disorder) and cloacal malformations (bladder exstrophy and epispadias complex) are also included in it.

Chromosomal DSD include Klinefelter syndrome and Turner syndrome.

Some children present early in life with atypical phenotype e.g. small phallus, undescended testis, perineal hypospadias with bifid scrotum and enlarged clitoris in a female child. Others are diagnosed late with problems of delayed puberty, unexplained infertility in males and with eunuchoid habitus in a male. ${ }^{9,10}$ Females usually present with delayed puberty, amenorrhea, indistinct sexual development or presence of hernia in female or there may be hirsutism etc.

Early diagnosis of such patients allows their brought up according to corrected sex.

The aim of the procedure is to produce better functioning and socially acceptable male or female.

The purpose of this study was to identify and categorize different presentations of DSD according to standardized category. ${ }^{11}$

Objectives: 1-To identify different presentations of DSD and categorize according to the standard categories of DSD. 2-To register the cases of DSD to I-DSD registry in Glasgow to be included in further clinical research.

\section{METHODOLOGY}

Study Design: Retrospective study.

Settings: Urology Department, Allied Hospital Faisalabad, Pakistan.

Duration: From 01-09-2008 to 31-08-2019.

Sample Technique: Non-Probability Consecutive Sampling.

Sample Size: 34

Inclusion Criteria: All the patients with ambiguous genitalia/indeterminate gender presenting to Urology Department of Allied Hospital Faisalabad irrespective of age were included in the study.

Exclusion Criteria: All the patients previously operated for DSD or with unrecorded data at first presentation because as it would change the presentation of the patients.
Methods: Relevant data was retrieved from patient's charts taken from hospital record with the permission of medical superintendent to publish their data.

Patients of ambiguous genitalia / indeterminate gender underwent detailed history and examination (under anesthesia where indicated). Karyotyping performed to detect the chromosomal sex. Ultrasonography was performed to localize internal genital organs. MRI and laparoscopy were also done to localize the internal genital organs and gonads, where needed. Laparoscopy was performed in selected cases to biopsy the rudimentary / indiscriminate / dysgenetic gonad. Laparoscopy was also performed therapeutically to bring down the undescended testis. Hormonal analysis like serum testosterone, serum FSH, LH and estradiol were obtained. Where diagnosis of $\mathrm{CAH}$ was suspected, blood level of 17 hydroxyprogesterone was done and, in case of younger age, serum electrolytes were also done. Serum dihydro-testosterone level were obtained where 5 alpha reductase deficiency was suspected. Baseline investigations were done to see the fitness of the patient. Vaginogram / sinogram was performed where rudimentary vagina suspected on Examination Under Anesthesia. Gender assignment was done after counselling of parents and adult patients. All the data will be uploaded to DSD registry in Glasgow to be used by other researchers in the world.

\section{RESULTS}

A total of 34 patients were registered. Mean age at presentation was $16.38 \pm 9.38$ years (ranged 10 months to 42 years).

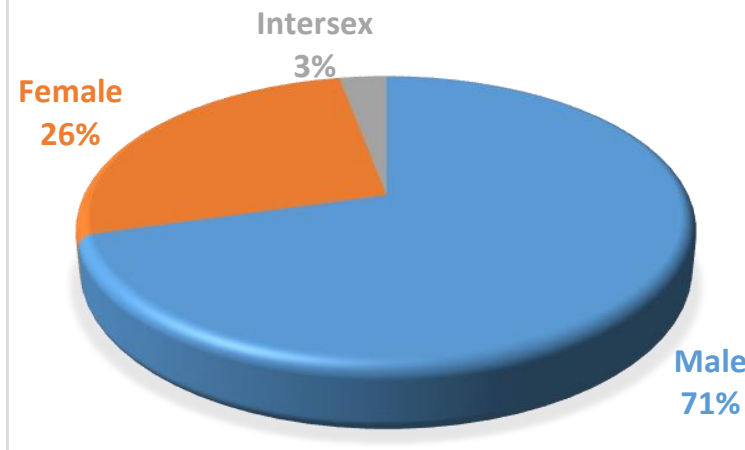

Figure 1: Percentage of patients brought up as male/female

Nine of 34 (26.47\%) patients were brought up as females, one $(2,94 \%)$ as intersex patient and 24 (70.58\%) as males.

Parents \& patients had presumed gender of their child according to phenotypic appearance, their divine wishes as well as social norms. For example, among the presumed female patients, 6 were chromosomally male, and all were having perineal hypospadias, bilateral undescended testes and small phallus. On the other hand, among the presumed male patients, two $(5.8 \%)$ were diagnosed as cases of $\mathrm{CAH}$ and parents assumed them males because of clitoral hypertrophy and labial fusion. However, principally, we assigned the gender according to the chromosomal sex. 
After categorization of various clinical presentations according to standard nomenclature, 27(79.4\%) belonged to 46XY DSD category, $03(8.80 \%)$ to $46 \mathrm{XX}$ DSD, $02(5.88 \%)$ to chromosomal DSD, 01(2.90\%) was 46XY complete gonadal dysgenesis and $01(2.90 \%)$ patient belonged to ovo-testicular DSD. None of the patients had 46XX testicular DSD. Among 27 patients of 46XY DSD category, $15(55.5 \%)$ patients had perineal hypospadias (majority with undescended testes), $07(25.92 \%)$ penoscrotal hypospadias (with undescended testes), 02 (7.4) complete androgen insensitivity syndrome, $02(7.4 \%)$ exstrophy epispadias complex \& 01 (3.7\%) had persistent Mullerian duct syndrome. In 46XX DSD category, two patients had congenital adrenal hyperplasia and one had bladder extrophy.

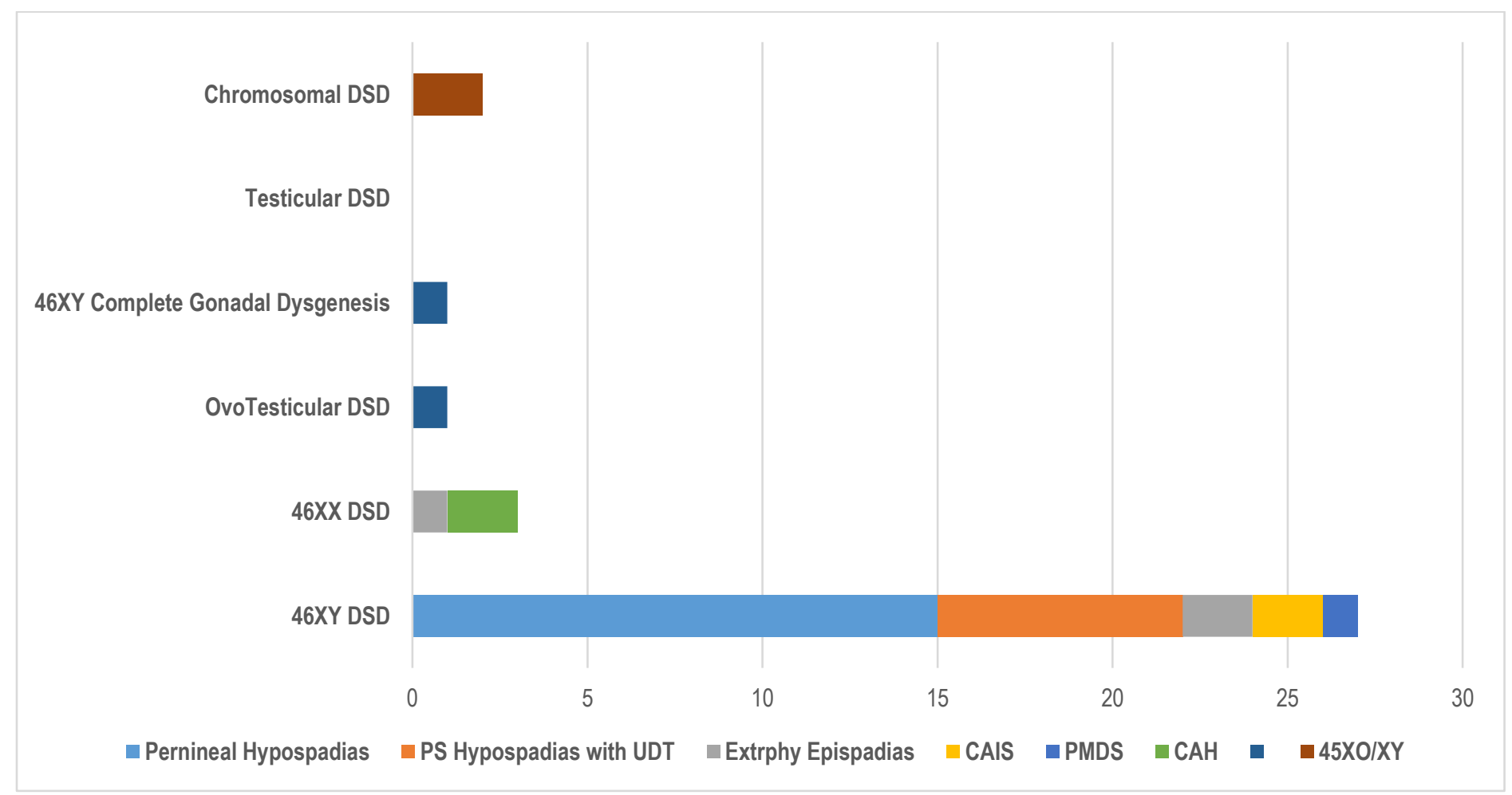

Figure 2: Categories of DSD $(n=34)$

PS Hypospadias with UDT: Penoscrotal Hypospadias with Undescended Testis

CAIS: Complete androgen insensitivity syndrome

PMDS: Persistent Mullerian Duct Syndrome

CAH: Congenital Adrenal Hyperplasia

\section{DISCUSSION}

DSD is a rare condition, with only 34 cases in Urology Department Allied Hospital, Faisalabad over period of 11 years, despite this center caters for about 20 million population and it was the only hospital in this area which is dealing with Pediatric Urology until 2017, when Children Hospital, Faisalabad became functional.

According to our data, only 9 (26.47\%) patients were brought up as female and $24(68.57 \%)$ were brought up as male and 1 as intersex while in a study conducted by Jaida Manzoor et al at Children Hospital, Lahore found $54.3 \%$ female patients and $43.7 \%$ as male. ${ }^{12}$ Among the $46 \mathrm{XXDSD}$ patients, $\mathrm{CAH}$ constitutes $66.66 \%$ while in study conducted in Lahore, $97 \%$ among XX DSD patients were diagnosed as having $\mathrm{CAH}$. One of our female patients was having bladder exstrophy. Another study conducted at Damascus about CAH patients $22.5 \%$ were male and $74 \%$ were female. In this study $90-95 \%$ patients of CAH were 21 hydroxylase deficiency and in our study $100 \%$ of
$\mathrm{CAH}$ patients were 21 hydroxylase deficiency. This is in consistent with Damascus study. ${ }^{13}$

Among the male patients, all were having hypospadias of varying degree with complex combinations of bifid scrotum and undescended testis. One of our male patients was having an exstrophy epispadias complex. Two of our male patients were diagnosed as cases of androgen insensitivity syndrome / $5 a$ reductase deficiency. This is in contrast with the study of Jaida Manzoor et al, where the most common defect was androgen insensitivity syndrome / $5 a$ reductase deficiencies which was shown in $81 \%$ of males and it is only $5.88 \%$ (of total 34 ) in our study.

We added cloacal malformation in our study as guided by I-DSD registry and these were not added in above mentioned study.

Two (5.8\%) of our patients were having chromosomal DSD and one was ovo-testicular DSD which is inconsistent with Children Hospital, Lahore study where only $2 \%$ were having sex chromosomal DSD and $2 \%$ were having ovo-testicular DSD. 


\section{CONCLUSION}

Patients \& families of this rare condition suffer socially \& psychologically due to indeterminate gender. Identification \& categorization of indeterminate sex is mandatory for gender assignment to make socially acceptable individuals.

\section{LIMITATIONS}

The data collected from only one department. Patients may have presented in Pediatric Surgery Department or Pediatric Medicine Department. Hence the number of cases may not depict the true prevalence.

\section{SUGGESTIONS / RECOMMENDATIONS}

Public awareness campaigns should be launched for early diagnosis and management of these patients.

\section{CONFLICT OF INTEREST / DISCLOSURE}

There is nothing to disclose and monetary benefit is not involved.

\section{ACKNOWLEDGEMENTS}

We acknowledge the I-DSD registry in Glasgow for their permission to upload our data to their data bank.

\section{REFERENCES}

1. Hughes IA, Houk C, Ahmed SF, Lee PA. LWPES consensus group, ESPE CONSENSUS group. Consensus statement on management of intersex disorders. Arch Dis Child. 2006;91(7):554-63.

2. Hughes IA, Houk C, Ahmed SF, Lee PA. Consensus statement on management of intersex disorders. J Pediatr Urol. 2006;2(3):148-62.
3. Emil A. Tanagho, Jack W. McAninch. SMITH, S GENERAL UROLOGY, 18th Edition, San Francisco, McGraw-Hill Education, 2012, page 676 .

4. Alan J Wein, Louis R. Kavoussi, Alan W. Partin, Craig A. Peters. Campbell-Walsh Urology, 11th edition, Philadelphia, Elsevier, 2016, page 2833.

5. Wilson TA, Bowden SA chief editor. Congenital adrenal Hyperplasia. emedicine.medscape.com. Cited on 14.6.19.

6. Frindik JP, Kemp $S$ chief editor. 3-Beta-Hydroxysteroid Dehydrogenase Deficiency. emedicine.medscape.com. cited on 14.6.19. https://emedicine.medscape.com/article/920621. overview.

7. Nordenstrom A, Rohle R, Thyen U, Bouvattier CHilczer JS, Reisch $\mathrm{N}$ et al. Hormone therapy and patient satisfaction with treatment, in a large cohort of diverse disorders of sex development. Clin Endocrinol. 2018;88(3):397-408.

8. Justin Al. Disorders/differences of sex development (DSD) for primary care: the approach to the infant with ambiguous genitalia. Transl Pediatr. 2017;6(4):323-34.

9. Lambert SM, Vilain EJ, Kolon TF. A practical approach to ambiguous genitalia in the newborn period. Urol Clin North Am. 2010;37(2);195-205.

10. Houk CP, Lee PA. Update on disorders of sexual development. Curr Oppin Endocrinol Diabetes Obes. 2012;19(1):28-32.

11. Witchel SF. Disorders of Sex Development. Best Pract Res Clin Obstet Gynecol. 2018:48:90-102.

12. Manzoor J, Aftab S, Yaqoob M. Ambiguous genitalia: An overview of 7 years' experience at the Children's Hospital \& Institute of Child Health, Lahore, Pakistan. Pak J Med Sci. 2019;35(1):151-5.

13. Sheikh Alshabab LI, Alebrahlm A, Kaddoura A, Al-Fahoum S. Congenital adrenal hyperplasia due to 21-hydroxylase deficiency: A five-year retrospective study in the Children's Hospital of Damascus, Syria. Qatar Med J. 2015;2015(1):11.

\section{AUTHORSHIP AND CONTRIBUTION DECLARATION}

\begin{tabular}{|c|c|c|}
\hline AUTHORS & Contribution to The Paper & Signatures \\
\hline $\begin{array}{l}\text { Dr. Muhammad Irfan Munir } \\
\text { Associate Professor, Urology, Faisalabad Medical } \\
\text { University / Allied Hospital, Faisalabad Pakistan }\end{array}$ & Manuscript Writing, Data Collection & \\
\hline $\begin{array}{l}\text { Dr. Muhammad Akmal } \\
\text { Associate Professor, Urology, Faisalabad Medical } \\
\text { University / DHQ Hospital, Faisalabad Pakistan }\end{array}$ & Results Compiling & \\
\hline $\begin{array}{l}\text { Prof. Dr. Ghulam Mahboob Subhani } \\
\text { Professor of Urology, Faisalabad Medical University } \\
\text { / Allied Hospital, Faisalabad Pakistan }\end{array}$ & Proof Reading, Final Layout & \\
\hline $\begin{array}{l}\text { Prof. Dr. Safdar Hassan Javed } \\
\text { Professor of Urology, Independent Medical College, } \\
\text { Faisalabad Pakistan }\end{array}$ & Literature Review & \\
\hline $\begin{array}{l}\text { Dr. Ashraf Ali Jafari } \\
\text { Consultant Urologist } \\
\text { Faisalabad Pakistan }\end{array}$ & Statistical Analysis & \\
\hline $\begin{array}{l}\text { Dr. Muhammad Tahir Bashir Malik } \\
\text { Assistant Professor of Urology, } \\
\text { Faisalabad Medical University / Allied Hospital, } \\
\text { Faisalabad Pakistan }\end{array}$ & Manuscript Writing & \\
\hline
\end{tabular}

